\title{
The examination of protective effects of gallic acid against damage of oxidative stress during induced-experimental renal ischemia-reperfusion in experiment
}

\author{
Canbek $\mathrm{M}^{1}$, Bayramoglu $\mathrm{G}^{2}$, Senturk $\mathrm{H}^{1}$, Oztopcu Vatan $\mathrm{AP}^{1}$, Uyanoglu $\mathrm{M}^{1}$, Ceyhan $\mathrm{E}^{1}$, Ozen $\mathrm{A}^{1}$, \\ Durmus $\mathrm{B}^{1}$, Kartkaya $\mathrm{K}^{3}$, Kanbak $\mathrm{G}^{3}$
}

Department of Biology, Faculty of Science, Eskisehir Osmangazi University, Eskisehir, Turkey. mcanbek@ogu.edu.tr

\begin{abstract}
Aim: In this study, probable effects of gallic acid were investigated in experimentally induced renal $\mathrm{I} / \mathrm{R}$ injury in rats.

Material and methods: For this purpose, each group consisted of 7 Spraque dawley male albino rats. Groups were defined as follows; Group I: control group; Group II: I/R group; Group III, IV and V: I/R+Gallic acid (50, 100 and 200 mg.kg-1 respectively-i.p.). Left kidney was removed by nephrectomy except for Group I. I/R was induced in the other kidney. Gallic acid was given 15 mins before ischemia induction. SOD, CAT and Gpx activities were determined by electrophoresis. MDA, MPO levels were determined spectrophotometrically. Histopathological investigations were also performed in kidney tissues. BUN and Creatinine levels in serum were determined. Results: BUN, Creatinine and MDA levels were statistically significant but MPO level was not statistically significantly increased in Group II. For SOD, CAT, Gpx activities in Group II, an increase was determined with respect to Group I. Histopathological investigations revealed widespread hyperemia in glomerulus, expansion of the structure between tubules and cell disruptions in Group II. In Group V (200 mg. $\mathrm{kg}^{-1}$ gallic acid), in terms of biochemical parameters, in spite of the significant decrease in BUN, Creatinine and MDA levels; a decrease was determined in SOD, CAT and Gpx isoenzyme activities. Group V showed histologically that I/R injury had been prevented to a greater extent and appearances were close to the control.

Conclusion: As a result, in terms of our study, evaluations regarding kidney functions and histopathology have shown that gallic acid has protective effects in renal I/R injury (Tab. 2, Fig. 5, Ref. 36). Text in PDF www.elis.sk. Key words: kidney, gallic acid, Ischemia-reperfusion, oxidative stress.
\end{abstract}

Ischemia is defined as the medical condition in which tissue's need for oxygen and other metabolites cannot be fulfilled by circulation and the formed residual products cannot be removed by circulation. Reperfusion is recovery of the blood flow to the tissue; however, ROSs (reactive oxygen species) that are released by PMNL (polymorphonuclearnuclear leukocytes) which comes and settles in the tissue during reperfusion can increase tissue damage (1). I/R (ischemia/reperfusion) damage is a series of incidents which is often encountered in the heart, liver, lung, kidney and intestines and leads to serious pathologies (2).

Harmful effects of ROSs are reduced or completely eliminated by antioxidants. In all intracellular places where oxygen is metabolized, antioxidants work fast and enzymatically in order to reduce the reactive oxygen metabolites. Endogenous antioxidants

${ }^{1}$ Department of Biology, Faculty of Science, Eskisehir Osmangazi University, Eskisehir, Turkey, ${ }^{2}$ Department of Biology, Faculty of Science, Artvin Coruh University, Artvin, Turkey, and ${ }^{3}$ Department of Clinic Biochemistry Faculty of Medical Science, Eskisehir Osmangazi University, Eskisehir, Turkey

Address for correspondence: M. Canbek, Mediha Canbek Department of Biology, Faculty of Science, Eskisehir Osmangazi University, 26480 Eskisehir, Turkey.

Phone: $+90.222 .2393750 / 2849$ which are effective in antioxidant defense are enzymatic antioxidants such as SOD (superoxide dismutase), CAT (catalase), Gpx (glutathione peroxidase) etc. (3).

With the studies carried out today, it is emphasized that $I / R$ damage in tissues can be prevented by some antioxidants to certain extents $(4,5)$.

It is underlined that flavonoids which show antioxidant characteristic are beneficial in terms of human health due to their ROS binding characteristics (6). It is reported that many phytoantioxidants play an important role in binding ROSs with their redox characteristics (7).

The gallic acid used in our study (3,4,5-trihydroxy benzoic acid) is a phenolic acid (Fig. 1) which is naturally contained by plants (8). Phenolic acids are contained in many plants which are important in human nutrition, such as tea, green tea, grape, sourberry (9). In the performed studies, it was reported that gallic acid has antibacterial, antifungal and strong anticarcinogenic effects (10-12).

It was reported that gallic acid and its esters are used as preservative ingredients both in food and pharmaceutical industries because of their antioxidant characteristics (13).

Some authors have showed in their studies that human promyelocytic leukemia, rat hepatoma, human epithelial carcinoma 
<smiles>O=C(O)c1cc(O)c(O)c(O)c1</smiles>

Fig. 1. Structural chemical formula of gallic acid.

and human hepatoma cells are very sensitive to gallic acid (10). It was reported that gallic acid protects cells better when compared to vitamin $\mathrm{E}$ and $\mathrm{C}$ by preventing LDL (low density lipoprotein) oxidation and therefore it is effective in diseases such as heart problems and atherosclerosis (14).

In this study, protective effects of gallic acid in renal I/R damage experimentally induced in male rats are biochemically and histologically evaluated.

\section{Materials and methods}

\section{Animals}

In this study, male Sprague dawley rats, 230-300 g of body weight were obtained from the T.R. Ministry of Health, Refik Saydam National Public Health Agency, Experiment Animals Production Laboratory. The experiment was performed following a stabilization period in the laboratory. They were housed in polycarbonate cages in an air conditioned room (12 Light/12 Dark, $22 \pm 2{ }^{\circ} \mathrm{C}, 50 \pm 5 \%$ humidity). Throughout the experimental period, animals were provided pellet chows and water was given ad libitum.

\section{Plant Material}

Gallic acid was obtained from sigma company (G7384). Gallic acid was solved in SF (saline solution).

\section{Experimental Design}

Animals were divided into 5 groups, each consisting of 7 animals. These groups were:

Group I sham - operated control group.

Group II right nephrectomy $+\mathrm{I} / \mathrm{R}+0.5 \mathrm{ml} \mathrm{SF}$

Group III right nephrectomy $+\mathrm{I} / \mathrm{R}+50 \mathrm{mg} \cdot \mathrm{kg}^{-1}$

Group IV right nephrectomy $+\mathrm{I} / \mathrm{R}+100 \mathrm{mg} \cdot \mathrm{kg}^{-1}$

Group V right nephrectomy $+\mathrm{I} / \mathrm{R}+200 \mathrm{mg} \cdot \mathrm{kg}^{-1}$

Right nephrectomy was performed under anesthesia (xylazin $10 \mathrm{mg}$ per $\mathrm{kg}$ and ketamine $70 \mathrm{mg}$ per $\mathrm{kg}$; intramuscular). Recovery of experimental animals in Groups II, III, IV and V was evaluated for 15 days after right nephrectomy. Gallic acid injections were applied into peritoneum 15 min before the ischemia process was performed. After $45 \mathrm{~min}$ of ischemia, reperfusion was applied for 6 hours. During reperfusion, as it was in the previous surgical application, sterile SF was given into abdominal cavity of each animal in order to prevent hypovolemic effects of the fluid loss after the surgery.

At the end of the experimental period all animals were euthanized by removing all blood intracardialy. Renal tissue samples were cut into two sections.

\section{Kidney histology}

The left kidney tissue samples were fixed in $10 \%$ neutral formaline for histological investigations. These tissues were routinely processed and embedded in parrafin. Sections of 5-6 $\mu \mathrm{m}$ thick were cut and stained with Harris Haematoxylin and Eosine (H\&E).

\section{Assessment of renal function}

The blood was collected and serum separated. The blood was collected and serum samples were stored at $-20{ }^{\circ} \mathrm{C}$ until serum level determinations were completed for BUN and Creatinine. Renal function was assessed by serum Creatinine and BUN (blood urea nitrogen) concentration (15). The blood samples were centrifuged and separated into serums for $10 \mathrm{~min}$ at $3000 \mathrm{rpm}$ through an Eppendorf $5804 \mathrm{R}$ model device. Creatinine and BUN measurements were performed by using commercial kit through Crony auto-analyzer.

\section{Preparation of renal tissues samples for analysis}

The left kidney tissue samples that were collected from all of the rats were stored under deepfreeze $\left(-80^{\circ} \mathrm{C}\right)$ conditions in order to examine CAT, SOD, Gpx, MDA (malondialdehyde) and MPO (myeloperoxidase) enzyme activities in the left kidney.

\section{Measurement of renal MDA and MPO activity}

Following the experiment, parts of liver were kept at $-80{ }^{\circ} \mathrm{C}$ in order to measure the levels of MDA and MPO (16-18).

\section{Qualitative analysis of antioxidant enzymes using native PAGE}

Activities of CAT, SOD and glutathione Gpx isoenzymes were determined in homogenized kidney. The protein content of supernatants was determined using Lowry's method (19) and bovine serum albumin as standard. Native-PAGE electrophoresis was performed at $+4{ }^{\circ} \mathrm{C} 120 \mathrm{~V}$ (for SOD and GPx) and $140 \mathrm{~V}$ (for CAT) as described by Laemmli (20). The enzymes were run on the basis of equal amounts of protein $(70 \mu \mathrm{g})$ in a $10 \%$ gel for SOD and Gpx and $8 \%$ gel for CAT. Electrophoretic separation was performed at $+4{ }^{\circ} \mathrm{C}$.

Determination of CAT activity was performed in accordance with the method of Woodbury et al (21). The enzyme appeared as a clear zone superimposed on a dark blue background.

Determination of SOD activity was performed in accordance with the method of Beauchamp and Fridovich $(22,23)$. The enzyme appeared as a clear zone superimposed on a green background.

The method of Lin et al was used to measure Gpx isoenzyme activity (23). The enzyme appeared as a clear zone superimposed on a violet background. The bands that showed the Gpx isoenzyme activity were observed as transparent color on a violet background.

Band areas, which were created by each isoenzyme activity, were measured by using the Kodak Gel Logic Imaging System. 
Tab. 1. BUN. Creatinine. MDA. MPO quantities determined in animals of the experimental group. Mean values \pm standard error values $(n=7)$.

\begin{tabular}{lccc}
\hline Groups & BUN $(\mathrm{mg} / \mathrm{dL})$ & Creatinine $(\mathrm{mg} / \mathrm{dL})$ & MDA (nmol/mg protein) \\
\hline I & $29.57 \pm 0.60$ & $0.47 \pm 0.02$ & $5.147 \pm 0.845$ \\
\hline II & $89.90 \pm 2.30^{\mathrm{a}}$ & $1.48 \pm 0.04^{\mathrm{a}}$ & $7.071 \pm 1.452^{\mathrm{a}}$ \\
\hline III & $84.91 \pm 2.97^{\mathrm{a}}$ & $1.32 \pm 0.04^{\mathrm{ab}}$ & $5.375 \pm 1.215^{\mathrm{b}}$ \\
\hline IV & $84.05 \pm 1.91^{\mathrm{a}}$ & $1.28 \pm 0.05^{\mathrm{ab}}$ & $0.00878 \pm 0.00653$ \\
\hline V & $82.20 \pm 2.55^{\mathrm{a}}$ & $1.10 \pm 0.03^{\mathrm{ab}}$ & $5.211 \pm 1.374^{\mathrm{b}}$ \\
\hline
\end{tabular}

$\mathrm{P}<.05$ there is a significant difference from a: Group I; b: Group II.

Tab. 2. Band areas (mm2) of CAT. SOD. Gpx enzyme activities determined on kidney tissue samples.

\begin{tabular}{|c|c|c|c|c|c|c|c|}
\hline \multirow[t]{2}{*}{ Groups } & \multirow[t]{2}{*}{$\begin{array}{l}\text { CAT } \\
\mathrm{mm}^{2}\end{array}$} & \multicolumn{2}{|c|}{$\begin{array}{l}\text { SOD } \\
\mathrm{mm}^{2} \\
\end{array}$} & \multicolumn{4}{|c|}{$\begin{array}{l}\mathrm{Gpx} \\
\mathrm{mm}^{2}\end{array}$} \\
\hline & & 1 & 2 & 1 & 2 & 3 & 4 \\
\hline I & 19.43 & 6.40 & 5.46 & 5.47 & 2.99 & 2.64 & 1.52 \\
\hline II & 57.36 & 14.69 & 14.53 & 29.58 & 25.05 & 18.21 & 17.23 \\
\hline III & 38.60 & 13.35 & 12.77 & 14.99 & 16.15 & 9.54 & 7.94 \\
\hline IV & 39.85 & 12.04 & 9.25 & 19.33 & 18.72 & 11.77 & 10.12 \\
\hline $\mathrm{V}$ & 23.48 & 10.93 & 9.58 & 9.74 & 5.81 & 5.38 & 4.10 \\
\hline
\end{tabular}

\section{Statistical analysis}

"SPSS 12 for Windows" package program was used for evaluation of the obtained data. MDA results with regard to the kidney tissue were analyzed according to One Way Analysis of Variance. "Fisher LSD Method" was used in relation to the multiple comparisons. MPO results were analyzed according to Kruskal-Wallis One Way Analysis of Variance on Ranks. Differences between the experimental groups were accepted to be significant if $\mathrm{p}<0.05$.

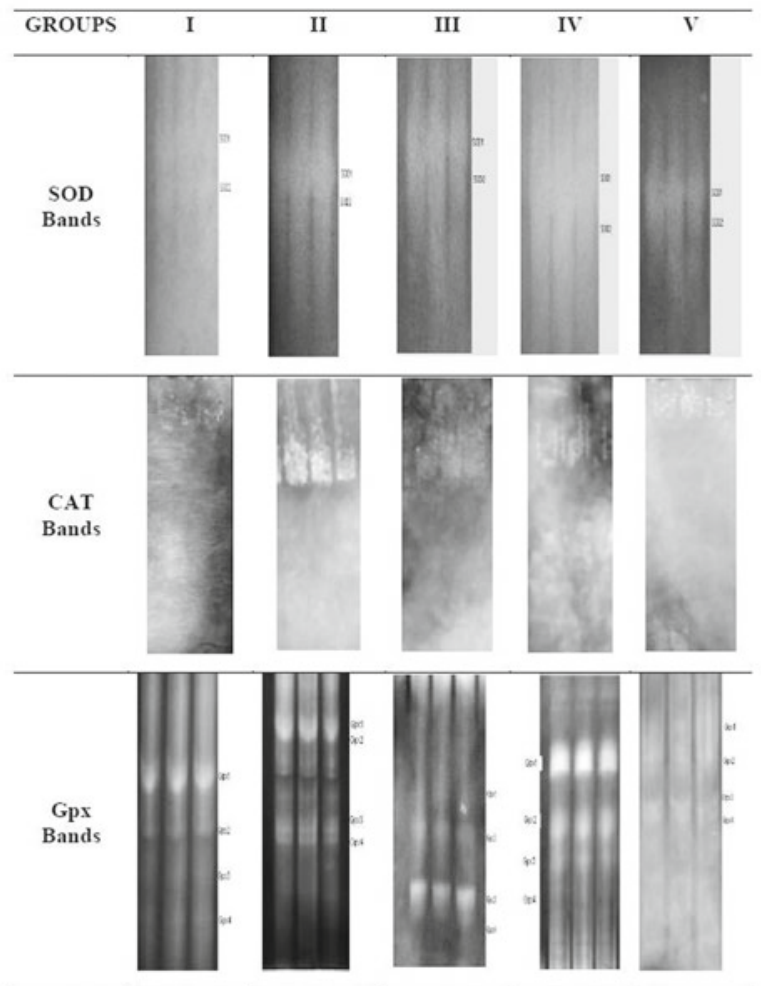

Fig. 2. Electrophoretic pattern of SOD, CAT, Gpx izoenzymes in kidney of rats.

\section{Results}

\section{Biochemistry}

While it was observed that Group I is significantly different from other groups in terms of serum BUN and Creatinine levels, no statistical difference was seen between other groups. It was observed that Creatinine level significantly decreased in Group $\mathrm{V}$ when compared to I/R group (Group II). While MDA level increased in I/R group (Group II), significant decreases were observed in Group III and IV. Any statistically significant differences cannot be found in terms of MPO level (Tab. 1).

\section{Isoenzyme activity}

In the kidney tissue samples, CAT isoenzyme was seen as a single band, SOD was seen as two bands (SOD1 and SOD2) and Gpx was seen as four bands (Gpx1, Gpx2, Gpx3, Gpx4) (Tab. 2, Fig. 2).

\section{Histological assessment of the kidney}

The kidney of control (Group I) rats showed a normal structure (Fig. 3). In the I/R group, generalized bleeding areas, PMNL migration, intratubular expansions and tubular deformation were seen (Fig. 4). In the I/R+200 mg. $\mathrm{kg}^{-1}$ gallic acid, tubule and glomerular structure close to the control group were observed (Fig. 5).

\section{Discussion}

With the decrease in renal blood flow and ensuing reperfusion, tissue damages at different levels develop in the organ. Restarting of blood flow in the ischemic tissue leads to two important results. The first one is the energy need being fulfilled and the second is toxic metabolites being removed from the environment. However, toxic metabolites returning into systemic circulation can increase the tissue damage even more. It is known that free radicals cause this damage. The studies carried out show that reoxidation increases the amount of ROS and antioxidant defense mechanism in the organism remains incapable (24). Antioxidants are molecules which try to prevent the damage caused by ROSs formed inside the cell. Phenolic compounds and some types of them are very effective in prevention of autooxidation. Flavonoids are phytopolyphenol compounds and cannot be synthesized by animal organisms (6). Effects of flavonoids on lipid oxidation are related to their capability to bind hydroxyl and superoxide radicals through electron transfer as a result of the reactions that they entered with peroxy-radicals (25). Gallic acid is also a polyphenolic compound with known antioxidant characteristic (26). 


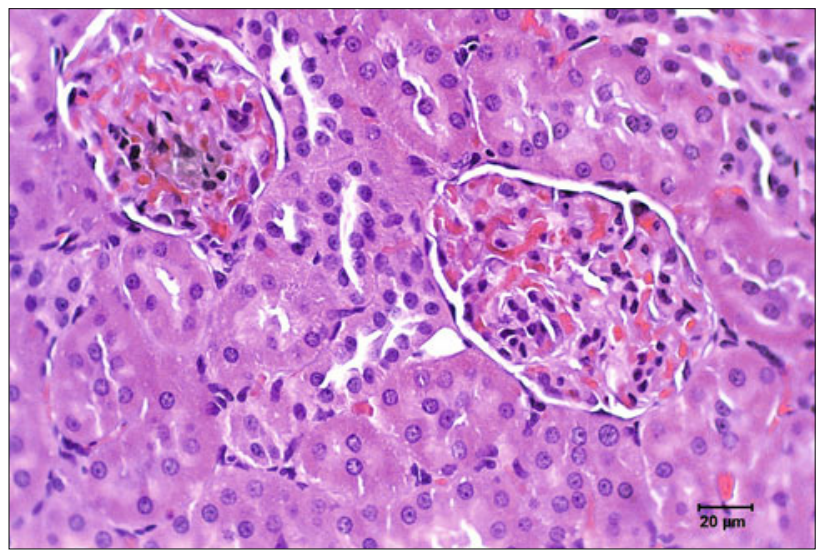

Fig. 3. Representative histological sections of the kidney obtained from Group I (Control group) H\&E (X40).

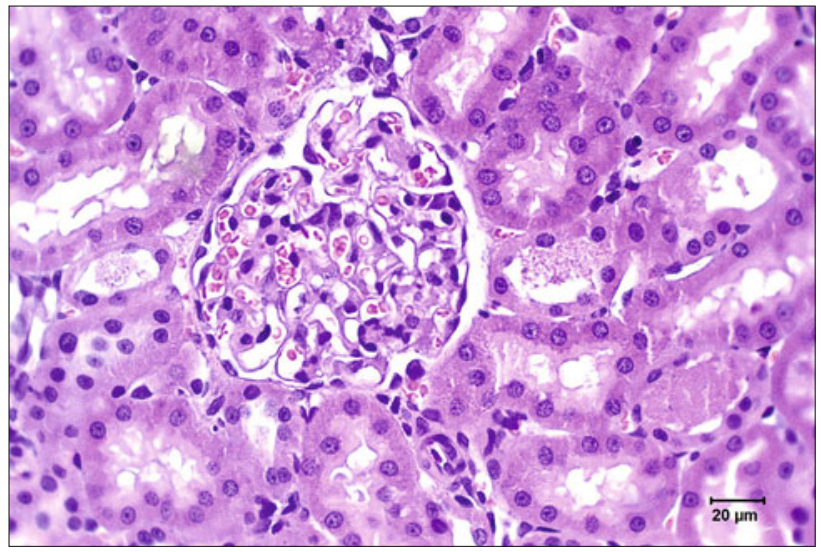

Fig. 4. Representative histological sections of the kidney obtained from Group II (I/R group) H\&E (X40).

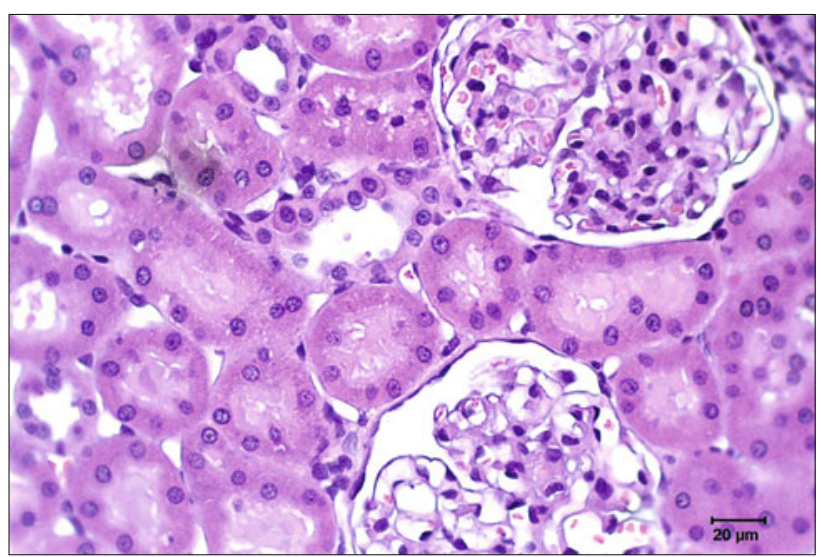

Fig. 5. Representative histological sections of the kidney obtained from Group V (I/R + 200 mg.kg-1 gallic acid) H\&E (X40).

When BUN and Creatinine levels obtained from blood serums after $45 \mathrm{~min}$ of ischemia/ 6 hours of reperfusion were examined in our study, an increase was observed in the I/R group when compared to the control group (Group I). BUN, which is an organic substance synthesized in the liver as the final product of protein destruction, is discharged from the kidneys with a passive reabsorption following the glomerular filtration and a tubular secretion. Therefore BUN values are related to the liver and kidney functions. This situation shows that I/R damage negatively affects the kidney functions. The daily amount of Creatinine which is discharged through urine is a significantly constant biological parameter. It is the most practical parameter which directly shows the glomerular filtration. Recovery was observed in Group $\mathrm{V}$ according to Creatinine levels. In our study, it was determined that serum BUN levels after I/R significantly increased in all the groups when compared to the control group. This situation shows that I/R negatively affects the kidney functions. Although a significant recovery was seen in other test parameters of Group V, it was determined that BUN level remained high. In conclusion, we think that $45 \mathrm{~min}$ of ischemia/6 hoursof reperfusion process significantly disrupted the kidney functions but did not critically affect the vitality of the kidney.

Korkmaz and Kolankaya (27) have compared serum Creatinine and BUN levels, oxidative stress and histologic parameters after single nephrectomy with the parameters of the rats to which nephrectomy has not been applied, and they reported that the values have not changed. On the other hand, they reported that oxidative stress and histological characteristics have changed in the rats to which 45 min of ischemia / 6 hours of reperfusion was applied. Similarly, there are several studies which show that increase in the serum urine amount after I/R causes renal failure (28).

Lipid peroxidation in free radical formation is closely related to the tissue damage due to $\mathrm{I} / \mathrm{R}$ and it is a good indicator showing the degree of MDA lipid peroxidation. In our study, we observed that MDA level increased in the I/R group. Statistically significant decreases were observed in Group III and IV. Sener et al (16) observed that MDA content of renal tissue increased in the I/R group after 45 minutes of ischemia and 6 hours of reperfusion when compared to the control group. In addition, they determined a decrease in the MDA amount in the I/R + Ginkgo biloba (50 mg. $\left.\mathrm{kg}^{-1}\right)$ group.

When we look at MPO parameter as neutrophil infiltration and activation parameter, an increase was seen in G2. It was reported that in post-ischemic state, PMNLs also lead to formation of ROS which has a role in ischemic damage because of myeloperoxidase enzyme that they consist of (29).

CAT, SOD, Gpx, which are present in living tissues, are very important antioxidant defense mechanisms. While CAT is responsible for detoxication of $\mathrm{H}_{2} \mathrm{O}_{2}$, SOD catalyzes $\mathrm{O}_{2}$ radicals; otherwise, biological structure and its membranes suffer damage. Gpx transforms $\mathrm{H}_{2} \mathrm{O}_{2}$ into water and oxygen. All of these play roles in formation of cellular damage. Decrease in activity of these enzymes is related to accumulation of high reactive free radicals. Decrease of these enzymes leads to an increase in free radicals, and as a result cell membranes lose their functions and integrity. These isoenzyme forms are very important in control of the regulation of cell metabolism (30).

In the electrophoretic analysis results of CAT enzyme in renal tissue, a single band appeared. While the band area in renal sample of Group I has a low intensity, the band in Group II was found as having high intensity. In Group III and IV, the band area was 
measured as being close to each other. In Group V, a decrease in the band area, which is close to Group I, was seen.

When SOD isoenzyme was searched in renal tissue, two isoforms were seen (SOD1 and SOD2). A low band area was observed in SOD1 isoform Group I. An increase was seen in Group II band area. Group III and IV displayed similar band areas. A decrease in band intensity of Group V was seen. When we evaluated it in terms of SOD2, low band area in Group I and high band area in Group II were seen. A decrease in the band area was determined in Group III. Similar results were obtained in Groups IV and V.

Four isoforms of Gpx enzyme were determined in renal tissue (Gpx1, Gpx2, Gpx3, Gpx4). Gpx1 isoform displayed a very low band area in kidney. All isoforms displayed very low band areas in Group I. In Group II, high band areas were seen. In Group III, a decrease was seen when compared to Group II. In Group IV, a decrease was seen when compared to Group I. In Group V, very low band intensity was determined.

Rasoulian et al (24) reported a significant increase in CAT and SOD levels in the I/R group after renal I/R (40 mins/6 hrs) in male Wistar rats in their study. In a similar study, Kapan et al (31) found a significant increase in SOD and CAT activities in ischemia group after aortic I/R. In these studies, it was emphasized that the enzyme activity increase after I/R is associated with oxidative stress. These results are similar with our study. On the other hand, there are studies which show that antioxidant enzymes decreased as a result of $\mathrm{I} / \mathrm{R}(5,32)$. Antioxidant enzyme activity after ischemia showed a significant increase in our study as well. We can say that the differences between the performed studies may probably result from the differences between methods, type and ischemia models.

In our study, it is deemed as a positive result of gallic acid that while antioxidant enzymes highly increased in group II, they decreased in Group III, IV and V.

We determined in our histological findings that tubular necrosis areas seen in the I/R group, prominent brush border losses, PMNL migration and tubular effusion decreased in GA groups depending on dose increase. In the light of these findings, we can say that gallic acid can be used as a SOR cleaning agent in prevention of renal I/R damage. Yeh and Yen (33) found in their studies that phenolic acids (gallic acid, gentisic acid, ferulic acid, p-coumaric acid) increase the antioxidant enzyme activity and showed that the antioxidant defense system increases in rat liver earlyafter the start of oral use of phenolic acids.

Krajka-Kuz'Niak and Baer-Dubowska (34) showed in their study that tannic acid triggers cytochrome $\mathrm{P} 450$ activity and phase II enzymes in rat liver and kidney. The same researchers observed hepatic SOD, CAT, Gpx and mRNA (messenger ribonucleic acid) expression in the liver tissues of the rats to which phenolic acid was given and showed that the levels of these enzymes change with phenolic acid intake.

Taking natural phenolic acids in diet (fruit, vegetable) is very important in terms of triggering antioxidant enzymes, and thus several chronic diseases (e.g. cancer and diabetes) can be prevented (35).

Jadon et al (36) reported that its resistance against carbon tetrachloride triggered kidney and liver damage is $200 \mathrm{mg} \cdot \mathrm{kg}^{-1}$ (p.o). The same researchers said that gallic acid does not protect only the plasma membrane, but also has a remedial effect on the liver and kidney. This also shows a parallelism with our results.

As a conclusion, we can say that enzymatic and nonenzymatic antioxidants (gallic acid) protect the kidney against oxidative stress by reducing peroxidation intensity through systems activity.

\section{References}

1. Baller MS. The Cell Biology of Reperfusion Injury in the Kidney. J Invest Med 1994; 42: 632-639.

2. Saba D, Yavuz H, Senkaya I et al. Kalsiyum Dobesilatin Iskelet Kasi Iskemi - Reperfuzyon Hasarindaki Rolu. Turkish J Thorac and Cardiovasc Surg 2000; 8: 797-801.

3. Granger DN, Korthuis RJ. Physiological Mechanisms of Postischemic Tissue Injury. Annu Rev Physiol 1995; 57: 311-332.

4. Kahraman A, Erkasap N, Serteser M, Koken T. Protective Effect of Quercetin on Renal Ischemia/Reperfusion Injury in Rats. J Nephrol 2003; 16: 219-224.

5. Singh D, Chander V, Chopra K. The Effect of Quercetine, a Bioflavonoid on Ischemia/Reperfusion Induced Renal Injury in Rats. Arch Med Res 2004; 35: 484-494.

6. Peterson J, Dwyer J. Flavonoids: Dietary Occurrence and Biochemical Activity. Nutrit Res 1998; 18 (12): 1995-2018.

7. Marwah RG, Fatope MO, Al Mahrooqi R, Varma GB, Al Abadi H, Al-Burtamani SKS. Antioxidant Capacity of Some Edible and Wound Healing Plants in Oman. Food Chem 2006; 101 (2007): 465-470.

8. Lu Z, Nie G, Elton PS, Ang H, Hao B. Structure-Activity Relationship Analysis of Antioxidant Ability and Neuroprotective Effect of Gallic Acid Derivatives. Neurochem Internat 2006; 48: 263-274.

9. Morton L, Caccetta R, Puddey I. Chemistry and Biological effects of Dietary Phenolic Compounds: Relevance to Cardiovascular Disease. Clin Exp Pharmacol Physiol 2000; 27: 152-159.

10. Sakaguchi N, Inoue M, Gihara Y. Reactive Oxygen Species and Intracellular $\mathrm{Ca}^{2+}$, Common Signals for Apoptosis Induced by Gallic Acid. Biochem Pharmacol 1998; 55: 1973-1981.

11. Akiyama H, Fujii K, Yamasaki O, Oono T, Watsuki K. Antibacterial Action of Several Tannins Against Staphylococcus aureus. J Antimicrob Chemother 2001; 48: 487-491.

12. Pellegrina CD, Padovani G, Mainente F et al. Anti-Tumour Potential of a Gallic Acid-Containing Phenolic Fraction from Oenothera biennis. Cancer Lett 2005; 226: 17-25.

13. Fuiza SM, Gomes C, Teixeira LJ. et al. Phenolic Acid Derivatives with Potential Anticancer Properties- a Structure-Activity Relationship Study. Part I: Methyl, Propyl and Octyl Esters of Caffeic and Gallic Acids. Bioorg Med Chem 2004; 12: 3581-3589.

14. Yilmaz Y, Toledo R. Health aspects of functional grape seed constituents. Trends Food Sci Technol 2004; 15: 422-433.

15. Ishibashi N, Weisbrot-Lefkowitz M, Reuhl K, Inouye M, Mirochnitchenko $\mathbf{O}$. Modulation of chemokine expression during ischemia/reperfusion in transgenic mice overproducing human glutathione peroxidases. J Immunol 1999; 163: 5666-5677.

16. Sener G, Sener E, Sehirli O, Ogunc A, Cetinel S, Gedik N. Ginkgo biloba extract ameliorates ischemia-reperfüsion-induced renal injry in rats. Pharm Res 2005; 52: 216-222. 


\section{$557-562$}

17. Canbek M, Uyanoglu M, Bayramoglu G et al. Effects of carvacrol on defects of ischemia-reperfusion in the rat liver. Phytomed 2008; 15: 447-452.

18. Shah PC, Brolin RE, Amenta PS, Deshmukh DR. Effect of aging on intestinal ischemia and reperfusion injury. Mech Ageing Dev 1999; 107: $37-50$.

19. Lowry O, Rosebrough N, Farr A, Randall R. Protein measurement with the Folin phenol reagent. J Biol Chem 1951; 193 (1): 265-275.

20. Laemmli UK. Cleavage of structural proteins during the assembly of the head of bacteriophage T4. Nature 1970; 227 (5259): 680-685.

21. Woodbury W, Spencer AK, Stahman MA. An improved procedure using ferricyanide for detecting catalase isozymes. Anal Biochem 1971; 44 (1): 301-305.

22. Beauchamp C, Fridovich I. Superoxide dismutase: improved assays and an assay applicable to acrylamide gels. Anal Biochem 1971; 44 (1): $276-287$.

23. Lin H, Chen H, Hou W. Activity staining og gluttathione peroxidase after electrophoresis on native and sodium dedocylsulfate polyacrylamide gels. Electrophoresis 2002; 23: 513-516.

24. Rasoulian B, Jafari M, Noroozzadeh A et al. Effects of IschemiaReperfusion on Rat Renal Tissue Antioxidant Systems and Lipid Peroxidation. Acta Med Iran 2008; 46 (5): 353-360.

25. Nijveldt RJ, Van Nood E, Van Hoorn DEC, Boelens PG, Van Norren K, Van Leeuwen PAM. Flavonoids: a Review of Probable Mechanisms of Action and Potential Applications. Am J Clin Nutr 2001; 74: 418-425.

26. Niho N, Shibutani M, Tamura $T$ et al. Subchronic toxicity study of gallic acid by oral administration in F344 rats. Food Chem Toxicol 2001; 39 (11): 1063-1070.

27. Korkmaz A, Kolankaya D. Protective effect of rutin on the ischemia/reperfusion induced damage in rat kidney. J Surg Res 2010; 164 (2): 309-315.
28. Roncal CA, Mu W, Croker B et al. Effect of Elevated Serum Uric Acid on Cisplatin-Induced Acute Renal Failure. Am J Physiol Renal Physiol 2007; 292: F116-F122.

29. Grisham MB, Hernandez CA, Granger N. Xanthine Oxidase and Neutrophil Infiltration in Intestinal Ischemia. Am J Physiol 1986; 251: $567-574$.

30. Kim SY, Lim JH, Park MR et al. Enhanced Antioxidant Enzymes Are Associated with Reduced Hydrogen Peroxide in Barley Roots Under Saline Stress. J Biochem Mol Biol 2005; 38 (2): 218-224.

31. Kapan S, Kiris I, Kilbas A, Altuntas I, Karahan N, Kutan H. Eritropoietinin sicçan aortik iskemi-reperfuzyonunda akciger hasari üzerine etkisi. Turk J Thorac Cardiovasc Surg 2009; 17: 110-116.

32. Chander V, Chopra K. Protective Effect of Nitric Oxide Pathway in Resveratrol Renal Ischemia- Reperfusion Injury in Rats. Arch Med Res 2006; 37 (1): 19-26.

33. Yeh CT, Yen GC. Induction of Hepatic Antioxidant Enzymes by Phenolic Acids in Rats Is Accompanied by Increased Levels of Multidrug Resistance-Associated Protein 3 Mrna Expression. J Nutr 2006; 136 (1): 11-15.

34. Krajka-Kuzniak V, Baer-Dubowska W. The Effects of Tannic Acid on Cytochrome P450 and Phase Enzymes in Mouse Liver and Kidney. Toxicol Lett 2003; 143: 209-216.

35. Hsu CL, Yen GC. Effect of Gallic Acid on High Fat Diet-induced Dyslipidaemia, Hepatosteatosis and Oxidative Stress in Rats. Br J Nutr 2007; 98 (4): 727-735.

36. Jadon A, Bhadauria M, Shukla S. Protective Effect of Terminalia Belerica Roxb. and Gallic Acid Against Carbon Tetrachloride Induced Damage in Albino Rats. J Ethnopharmacol 2007; 109 (2): 214-218.

Received March 13, 2013. Accepted March 25, 2014. 